\title{
Role of Impedance Audiometry in Evaluation of Eustachian Tube Function and Its Correlation with Tympanoplasty Surgery Outcome: Our Experience
}

\author{
Kanchan Rahul Tadke ${ }^{1}$, Vaibhav J Lahane ${ }^{2}$, P.T.Wakode ${ }^{3}$ \\ ${ }^{1}$ Associate Professor Department of ENT Government Medical College and Hospital, Nagpur, Maharashtra, \\ India. \\ ${ }^{2}$ Senior Resident Department of ENT Government Medical College and Hospital, Nagpur, Maharashtra, India. \\ ${ }^{3}$ Dy.Director Director of Medical Education and Research, Mumbai, Maharashtra, India
}

\begin{abstract}
:
Background: Normal Eustachian tube function is one of the important factor required for successful tympanoplasty outcome. A clinically useful test for assessment of Eustachian tube function is still lacking.

Aims And Objectives: To evaluate Eustachian tube function by impedance audiometry and compare the outcome of surgery with respect to graft take up in normal and abnormal Eustachian tube function.

Study design - Prospective study.

Materials and Methods: Study includes 60 patients diagnosed as chronic suppurative otitis media, mucosal type in quiescent or inactive stage. All patients were evaluated with detailed history, ENT examination and radiological investigations. Eustachian tube function was assessed with impedance audiometry. Preoperative Eustachian tube function results were compared with postoperative surgical outcome and results were analyzed. Results: On impedance audiometry $65 \%$ patients had normal Eustachian tube function and $35 \%$ had impaired function. Overall graft take up rate was $91.66 \%$ and failure rate was $8.34 \%$. Tympanoplasty was successful in 94.87\% patients with normal Eustachian tube function and in $85.71 \%$ with impaired function and difference was not statistically significant $(P>0.05)$. Hearing improvement in terms of air-bone gap closure (AB gap <20db) was more in patients with normal Eustachian tube function (61.66\%).

Conclusion: Impedance audiometry is a simple and easy method to assess Eustachian tube function. It not merely assess the anatomical patency but also the physiological function of Eustachian tube. Outcome of Tympanoplasty would be a success in normal Eustachian tube function but impaired tubal function should not be the ground for refusal of surgery.
\end{abstract}

Keywords: Tubotympanic disease, Type I Tympanoplasty, Eustachian tube function, Impedance Audiometry.

\section{Introduction}

Eustachian tube serves the function of ventilation, pressure balance and clearance of secretions in middle ear. Eustachian tube function (ETF) has been the center of focus as a prognostic factor because of its presumed primary role in the pathogenesis of otitis media and in clearance of the middle ear cavity (1). Success of Tympanoplasty depends on many factors, one of which is adequate Eustachian tube function. It was believed that tubal dysfunction is one of the most important factors for failure of Tympanoplasty (2).

Overtime many methods were evolved to evaluate ETF which includes sonotubometry, radiological studies and photoelectric method to measure patency, assessment of ventilator capacity of Eustachian tube using a sound proof chamber and use of fluorescein or saccharine to measure mucociliary clearance time. But all these methods are rather complex and facilities for the same are not available at many places. The newer generation impedance audiometer offers the facility to evaluate ETF in a much easier, simpler and user friendly way. Impedance audiometry helps to assess the physiological function of Eustachian tube which is much more important than mere assessment of anatomical patency of the tube. The present study was undertaken to assess the ETF by impedance audiometry in patients with Chronic Suppurative Otitis Media - mucosal type with reference to its treatment outcome. AZ-26 of Interacoustics impedance audiometer was used to assess the ETF.

\section{Materials And Methods}

The Prospective study comprised of 60 patients of Chronic Suppurative otitis media (CSOM) with central perforation attending ENT OPD of a tertiary care hospital for a period of 2 years.

Inclusion criteria - Patients in the age group of 18-45 years, with Tubotympanic type of CSOM, having no source of active infection in ear, nose and throat and having good cochlear reserve were included in the study. Exclusion criteria - Patients with Atticoantral CSOM, revision tympanoplasty, associated with any other source of infection in ENT, those with SNHL were excluded from the study. 
All patients were evaluated with detailed history, ENT and systemic examination, otomicroscopy and radiological investigations like X-ray mastoid schuller's view and paranasal sinuses. Pure tone audiometry was done with ALPS - Advanced Digital Audiometer AD- 2000 in a sound treated room. Preoperative ETF was tested with AZ- 26 of Interacoustic impedance audiometer. Details of Eustachian tube function test were applied as follows:

The impedance audiometer was programmed to artificially increase or decrease the air pressure at middle ear and then record the change of air pressure in the middle ear each time the patient swallows. The air pressure at middle ear end of Eustachian tube was first changed either +250 or $-250 \mathrm{~mm}$ of $\mathrm{H} 2 \mathrm{O}$ (daPa) and patient was then asked to swallow repeatedly to ascertain whether the positive or negative pressure was being partially neutralized with each swallow. The air pressure of the middle ear was monitored and recorded graphically by impedance audiometry. Any change of pressure during swallowing was recorded as a step ladder type of graph. When the subject swallows and the Eustachian tube opens, there is sudden change in the middle ear pressure. Immediately after this, the Eustachian tube closes passively and the middle ear pressure becomes steady. Again when the subject swallows, the middle ear pressure suddenly changes. Normally, the positive or negative middle ear pressure should be partially neutralized with each swallow and in three to five swallows the pressure should totally neutralize i.e. it should read $0 \mathrm{~mm}$ of $\mathrm{H} 2 \mathrm{O}$ (figure No 1). Any deviation from this is considered abnormal. If some residual pressure persists even after five swallows, the tubal function is considered to be impaired (figure No. 2). All patients were subjected to Type I tympanoplasty by postaural or endaural route with underlay technique of graft placement. Temporalis fascia was the graft material of choice. Follow up was done at $1^{\text {st }}, 2^{\text {nd }}, 4^{\text {th }}, 6^{\text {th }}$ and $8^{\text {th }}$ week. After successful closure of perforation, pure tone audiogram was done at $8^{\text {th }}$ week post-operatively.

\section{Results And Observations -}

60 patients between age group of 18 to 45 years with mucosal type of CSOM, either in inactive or quiescent stage were included in study. All cases were of unilateral ear disease. $40 \%$ patients $(24 / 60)$ were in the age group of 18-20 years. Male to female ratio was 1: 2.3.Otorrhoea was the main complaint in all cases with $53.33 \%$ patients $(32 / 60)$ having duration of discharge between 1-10yrs. Majority of patients were seen in quiescent stage of the disease i.e 65\% (39/60) during first visit

On otoscopy, 35 patients $(58.33 \%)$ had large central perforation whereas $22(36 \%)$ had moderate and 3 patients $(5 \%)$ had small perforation. 51.66\% (31/60) patients had preoperative air bone (AB) gap between 30$45 \mathrm{~dB}$ whereas $46.66 \%$ (28/60) patients had AB gap between 15-30dB and $1.66(1 / 60)$ patient had more than 45 $\mathrm{dB}$. On impedance audiometry it was found that $65 \%$ (39/60) patients had normal Eustachian tube function and $35 \%$ (21/60) patients had impaired ETF. All patients underwent type I Tympanoplasty. Follow up were done at $2^{\text {nd }}, 4^{\text {th }}, 6^{\text {th }}$ and $8^{\text {th }}$ weeks. Graft take up was assessed at each visit and hearing improvement was evaluated at $8^{\text {th }}$ week by pure tone audiometry. Association between Eustachian tube function and graft take up was studied. In the normal Eustachian tube function group, out of 39, graft take up was seen in 37 cases( $(94.87 \%)$ and rejection in 2 cases $(5.12 \%)$. In impaired ETF group, out of 21 cases, graft take up was seen in 18 cases $(85.71 \%)$ and rejection in 3 cases $(14.28 \%)$ (Table No 1). Postoperatively, the air bone gap at 2 months follow up was reduced to less than $10 \mathrm{~dB}$ in $11(18.33 \%)$ cases with normal tubal function and $1(1.66 \%)$ case of impaired tubal function. Air bone gap of $>30 \mathrm{~dB}$ was seen in $1(1.66 \%)$ case of normal and $1(1.66 \%)$ case of impaired tubal function (Table No 2 and Figure No 3).

\section{Discussion}

The ETF has been the center of focus as a prognostic factor because of its presumed primary role in the pathogenesis of otitis media and in the aeration of middle ear cavity. The ETF is the most important determinant of surgical outcome in patients with CSOM (Tubotympanic type) (3). A properly functioning Eustachian tube is an integral part of a normally functioning middle ear and the existence of good tubotympanic mucociliary drainage constitutes a favorable prognostic factor in the outcome of tympanoplasty (4). ETF is implicated in tympanoplasty failure both primarily through middle ear pressure dynamics and secondarily through recurrent otitis media (1). A preoperative test of tubal function is, therefore, of great interest, especially if such a test provides a possibility of estimating the chances of achieving a satisfactory result of tympanoplasty.

The age range of patients in this study was 18-45 years with mean age of 25.9 years. A study conducted by Shiromany et al had patients in age range from 12 to 64 years and mean age was $26.7 \pm 10.18$ years $(\mathbf{5})$. The mean age of patients in the present study was comparable with the other studies (6-8).Maximum patients i.e. $40 \%$ (24/60) were in age range of 18-20 years. As second decade of life is the most active time of one's life more people seek medical advice for discharging ear.

In the present study male to female ratio was 3:7. Holmquist in his study of 72 cases also showed female preponderance with 31 males and 41 females (9). Literature does not show any predilection for females (10-13). However, when a female patient attends a marriageable age i.e 18-20 years, awareness suddenly 
arouses in the patient and parents to prevent the discredit of discharging ear and hence females pay more attention to discharging ear than the male counterpart. Duration of otorrhoea suggests that CSOM usually being painless condition patients do not come for consultation even when the duration of discharge is 10 years or more. Only 3.33\% patients reported to OPD within one year of complaints of otorrhoea and this is very important scenario in Indian society.

In this study, Eustachian tube function was tested with impedance audiometry. Physiologically the neutralization of the negative middle ear pressure is brought about by intermittently opening the Eustachian tube and allowing air to pass through it such that the air pressure within the middle ear cavity is brought back more or less to the same level as that of the atmospheric air pressure. The intermittent opening of the Eustachian tube is caused by contraction of the tensor palatini and partially the levetor veli palatini muscles. These muscles contract during swallowing. Hence for assessment of Eustachian tube function, it has to be essentially ascertained whether an artificially increased or decreased middle ear pressure can be neutralized and brought back to ambient pressure by swallowing. The newer generation of impedance audiometers allow us to monitor and document whether swallowing balances the middle ear pressure and thereby test the Eustachian tube function very precisely and effectively. It has been established that the monitoring of the opening of the Eustachian tube and the resultant neutralization of the middle ear pressure on swallowing is much more accurate when there is a pressure differential $(\mathbf{1 4 , 1 5})$. A pressure differential is possible only by using the impedance audiometer. The impedance audiometer builds up a positive or negative pressure.at the middle ear end of tube whereas the pressure at the nasopharyngeal end of the tube remains at $\mathrm{O}$ daPa (atmosphere pressure). Without this pressure differential, the test is positive in only one third of the patients who have normal function, which means that without this pressure differential the false negative rate is very high. Herein lies the importance of functional assessment of Eustachian tube using the impedance audiometer.

Eustachian tube patency test showed that out of 60 cases, 39 (65\%) were having normal ETF and 21 (35\%) were having impaired function. Study carried by different authors showed a variation in the percentage of Eustachian tube function. Normal ETF was observed as $51 \%$ by Holmquist (9), Sidentop showed $16 \%$ (16), Sharp $7.5 \%$ (17) and Dutta 26\% (18). This difference may be because the different authors used different methods to evaluate the Eustachian tube function and at different time of disease activity.

Postoperatively it was found that out of 39 cases with normal Eustachian tube function graft take up was seen in $37(61.66 \%)$ cases and rejected in $2(3.33 \%)$ cases. On the other hand, 21 cases had impaired Eustachian tube function and out of them, 18 (30\%) cases had graft take up and $3(5 \%)$ had graft failure. The results of present study are comparable with Mackinnon (19) who observed $81 \%$ success rate in patients with normal ETF and 40\% in patients with impaired ETF. Study results were compared with other studies in table No 3 (20-24). After applying the tests of significance it was found that there is no significant association between Eustachian tube function and successful graft take up $(\mathrm{P}>0.05)$. Other authors like Sheehy and Glasscock (25), Sharp (17), Ekvall (26), Bluestone (27), Anderson (28), too observed poor correlation between Eustachian tube function and Tympanoplasty results. They observed more than $70 \%$ success rate in patients with poor tubal function.

Holmquist (9) in his study found high percentage of graft take up rate in poor Eustachian function test group and hence no one should be refused surgery merely on the basis of poor Eustachian tube function preoperatively. In the present study, we have found hearing improvement more in patients with normal Eustachian tube function with reduction in air bone gap less than $10 \mathrm{~dB}$ in $18.33 \%(11 / 60)$ patients than in impaired tubal function with reduction in air bone gap less than $10 \mathrm{~dB}$ in only $1(1.66 \%)$ patient. Holmquist (9) states that the results were almost same in both, normal and impaired function group. Mackinnon (19) observed failure in hearing improvement in $31 \%$ cases of severe hypofunction whereas in normal function group only 13\% had failed to improve in hearing postoperatively. According to Anirban Biswas (29), the incidence of failure of tympanoplasty was much higher amongst patients having poor Eustachian tube function $(70.84 \%)$ prior to the surgery. On the contrary, it was found that the success rate in tympanoplasty (i.e. perfect uptake of graft without retraction or post-operative adhesions and post-operative air bone gap of less than 30dB) was much higher $(76.31 \%)$ in ears which had normal tubal function prior to the surgery. In the present study, statistical evidence showed that Eustachian tube function does not play a much significant role in graft take up. However to be too dogmatic, a large series study for prolonged period is needed.

\section{Conclusion -}

As a good conduit of ventilation and pressure balance in middle ear, normally functioning Eustachian tube plays important role in tympanoplasty surgery in terms of successful graft take up and hearing improvement. But this does not mean that impaired Eustachian tube pose a ground for refusal of tympanoplasty surgery. The ventilatory function of the Eustachian tube can be reliably measured by the modern impedance audiometers (AZ-26 Interacoustics) without any difficulty and in an user friendly way. Thus, making the impedance audiometer a very valuable tool in the otologist's diagnostic armamentarium. 
Ethical Approval - This article does not contain any studies with animals performed by any of the authors.

Informed Consent - Informed consent was obtained from all individual participants included in the study.

Conflicts of Interest - Authors declare that they have no conflicts of interest.

\section{References}

[1]. Manning SC, Cantekin EI, Kenna MA, et al. Prognostic value of eustachian tube functions in paediatric tympanoplasty. Laryngoscope 1987; 97:1012-6.

[2]. M Tos. Tubal function and tympanoplasty. Journal of Laryngology and Otology, 1973, 1113-1124.

[3]. Tos M. Importance of Eustachian tube function in middle ear surgery. Ear Nose Throat J 1998; 77:744-7.

[4]. Gimenez F, Algarra M. The prognostic value of mucociliary clearance in predicting success in tympanoplasty. J Laryngol Otol 1993; 107:895-7

[5]. Shiromany A, Belaldavar BP. Effect of Eustachian tube function on tympanoplasty outcome in chronic otitis media patients: Crosssectional study. Indian Journal of health sciences 2016; 9: 279-83.

[6]. Prasansuk S, Hinchcliffe R. Tympanic membrane perforation descriptors and hearing levels in otitis media. Audiology 1982; 21:43- 51.

[7]. Pannu KK, Chadha S, Kumar D, Preeti. Evaluation of hearing loss in tympanic membrane perforation. Indian J Otolaryngol Head Neck Surg 2011; 63:208- 13 .

[8]. Mehta RP, Rosowski JJ, Voss SE, O’Neil E, Merchant SN. Determinants of hearing loss in perforations of the tympanic membrane. Otol Neurotol 2006; 27:136- 43

[9]. Holmquist. The role of Eustachian tube in myringoplasty. Acta otolaryngologica.1968,66:289-295.

[10]. Prasad KC, Hegde MC, Prasad SC, Meyappan H. Assessment of eustachian tube function in tympanoplasty. Otolaryngol Head Neck Surg 2009; 140: 889- 93

[11]. Malik S, Khalid A, Zahid S, Salman A, Ahmed N. Determinants of variable hearing loss in patients with chronic suppurative otitis media. Pak J Otolaryngol 2012; 28:45.7.

[12]. Maharjan M, Kafle P, Bista M, Shrestha S, Toran KC. Observation of hearing loss in patients with chronic suppurative otitis media tubotympanic type. Kathmandu Univ Med J 2009; 7: 397.401.

[13]. Ibekwe TS, Nwaorgu OG, Ijaduola TG. Correlating the site of tympanic membrane perforation with hearing loss. BMC Ear Nose Throat Disorder 2009;9:1.

[14]. Perlman HB : (1967) Normal tubal function. Arch Otolaryngol ,86:58

[15]. Ingelstedt 5 et al (1967) Mechanics of Human Middle ear Acta Otolarngol Suppl, 228.

[16]. Sidentop K.H., Eugene Tardy et al. Eustachian tube function. Arch otolaryngol, 1968,88: 66-75.

[17]. Sharp Malcom. The manometric investigation of tubal function with reference to myringoplasty results. The journs Laryngo otol (1970) 545-557.

[18]. Dutta N.N., Kacker S.K. et al. Eustachian tube function in health and disease. Ind Journal of Otol. 1971,23: 163-175.

[19]. Mackinnon D M. Relationship of preoperative Eustachian tube function in myringoplasty. Acta Otolaryngol,1970,69:100-106.

[20]. Moustafa MH, Salim M et al. Simple apparatus for assessment of Eustachian tube patency before myringoplasty. Journal of laryngology and otology, 1979,93:39-42.

[21]. Sengupta RP, Kacker SK. Study of Eustachian tube function with particular reference to long term follow up in myringoplasty. Ind Journ otol, 1974,26: 132-137.

[22]. Cohn AM, Schwaber MK, Anthony LS, Jerger JF. Eustachain tube function and tympanoplasty. Ann Otol 1979; 88:339-47.

[23]. Sen S, Guha S, Biswas A, Ghosh LM. A comparative study of methods of evaluation of Eustachian tube functions in chronic otitis media. Indian J Otol 1998; 4:147-9.

[24]. Kanagamuthu Priya, Padmanabhan Karthikeyan, Venkataramanujam Nirmal Coumare, Alandur Ponnusamy Sambandan. Evaluation of eustachian tube function in chronic suppurative otitis media (tubotympanic type) with reference to its treatment outcome. Indian Journal of Otology. October 2012, Vol 18,Issue 4.

[25]. Sheehy and Glasscock. Archieves of Otolaryngology, 1967,86: 361.

[26]. Ekvall. Eustachian tube function in tympanoplasty. Acta otolaryngol 263:33-42.

[27]. Bluestone CD, Cantekin El. Eustachian tube function related to the resultsd of tymapnoplasty in children. The laryngoscope,1979, 89:450-458

[28]. Anderson L, Harris S. middle ear mechanics and Eustachian tube function in tympanoplasty. Acta otolaryngol stockh supply. 1979,360:141.

[29]. Anirban Biswas. Eustachian Tube Function test: a new dimension in the management of CSOM. IJO \& HNS. Vol. 1, No. 2, AprilJune,1999 IJO \& HNS. Vol. 1, No. 2, April-June, 1999.

Table no 1 Relationship between preoperative Eustachian tube function and graft take up.

\begin{tabular}{|c|c|c|c|}
\hline Preoperative tubal function & Total no of patients & Graft take up & Failure \\
\hline Normal & 39 & $37(94.87 \%)$ & $2(5.12 \%)$ \\
\hline Impaired & 21 & $18(85.71 \%)$ & $3(14.28 \%)$ \\
\hline Total & 60 & $55(91.66 \%)$ & $5(8.33 \%)$ \\
\hline
\end{tabular}

Table no 2 Relationship between Eustachian tube function and closure of air bone (AB) gap at 2 months.

\begin{tabular}{|c|c|c|c|c|c|}
\hline $\begin{array}{c}\text { Eustachian tube } \\
\text { function }\end{array}$ & $<10 \mathrm{~dB}$ & $11-20 \mathrm{~dB}$ & $21-30 \mathrm{~dB}$ & $>30 \mathrm{~dB}$ & Total \\
\hline Normal & $11(18.33 \%)$ & $26(43.33 \%)$ & $1(1.66 \%)$ & $1(1.66 \%)$ & $39(65 \%)$ \\
\hline Impaired & $1(1.66 \%)$ & $17(28.33 \%)$ & $2(3.33 \%)$ & $1(1.66 \%)$ & $21(35 \%)$ \\
\hline
\end{tabular}


Table no 3 Correlation of Eustachian tube function and Tympanoplasty outcome

\begin{tabular}{|l|l|l|}
\hline Authors & Success rate in Normal ETF & $\begin{array}{l}\text { Success rate in Impaired } \\
\text { ETF }\end{array}$ \\
\hline Holmquist et al 1968(9) & $75 \%$ & $12 \%$ \\
\hline Mackinnon et al 1970 (19) & $81 \%$ & $40 \%$ \\
\hline Moustafa et al 1976(20) & $100 \%$ & $80 \%$ \\
\hline Dutta et al 1971 (18) & $87.5 \%$ & $69 \%$ \\
\hline Sengupta et al 1974(21) & $91.3 \%$ & $70.5 \%$ \\
\hline Prasad KC et al 2009(10) & $93.75 \%$ & $68.42 \%$ \\
\hline Cohn et al. 1979 (22) & $95 \%$ & $75 \%$ \\
\hline Sen et al. 1998 (23) & $80 \%$ & $80 \%$ \\
\hline Shiromany and Belaldavar et al 2016(5) & $90.2 \%$ & $63.6 \%$ \\
\hline Priya et al 2012(24) & $100 \%$ & $98 \%$ \\
\hline Present study & $\mathbf{9 4 . 8 7 \%}$ & $\mathbf{8 5 . 7 1 \%}$ \\
\hline
\end{tabular}

Figure 1- Tympanogram showing normal tubal function

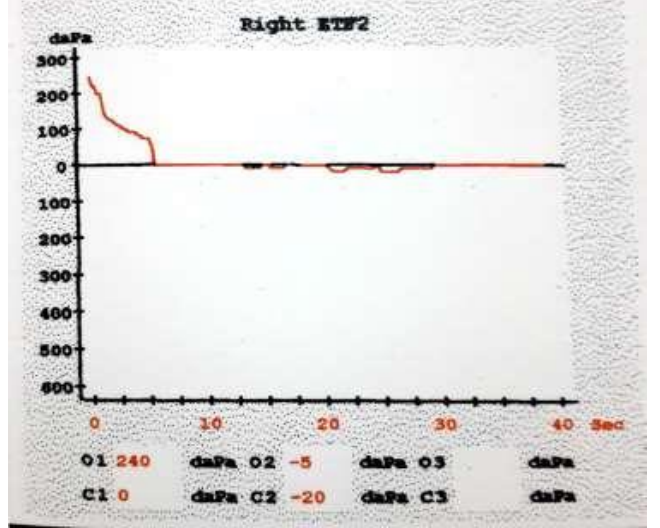

Figure 2 - (a) - Tympanogram showing partially impaired tubal function. (b) - Tympanogram showing grossly impaired tubal function.

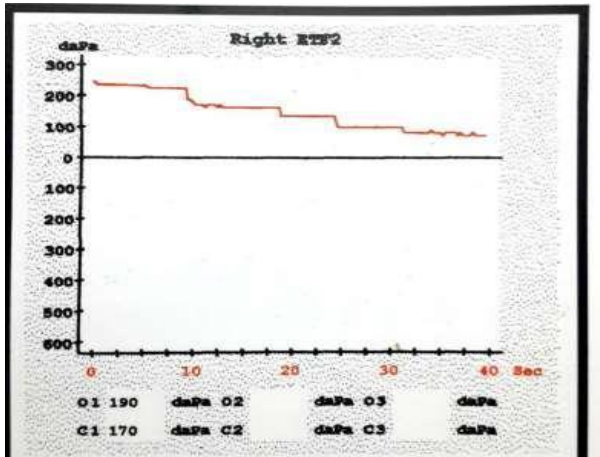

(a)

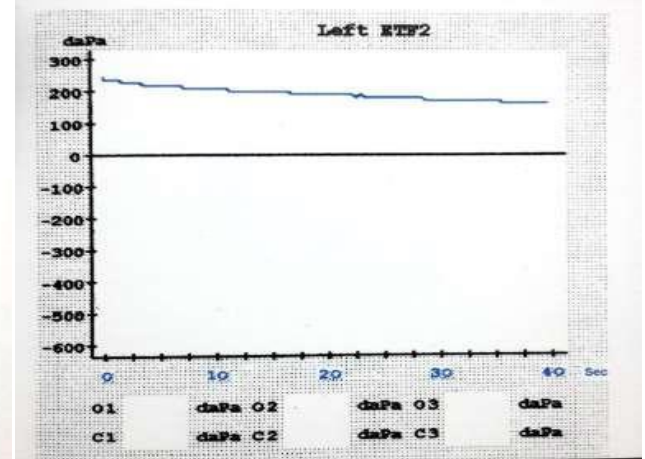

(b)

Figure 3 - Relationship between Eustachian tube function and closure of air bone (AB) gap at 2 months

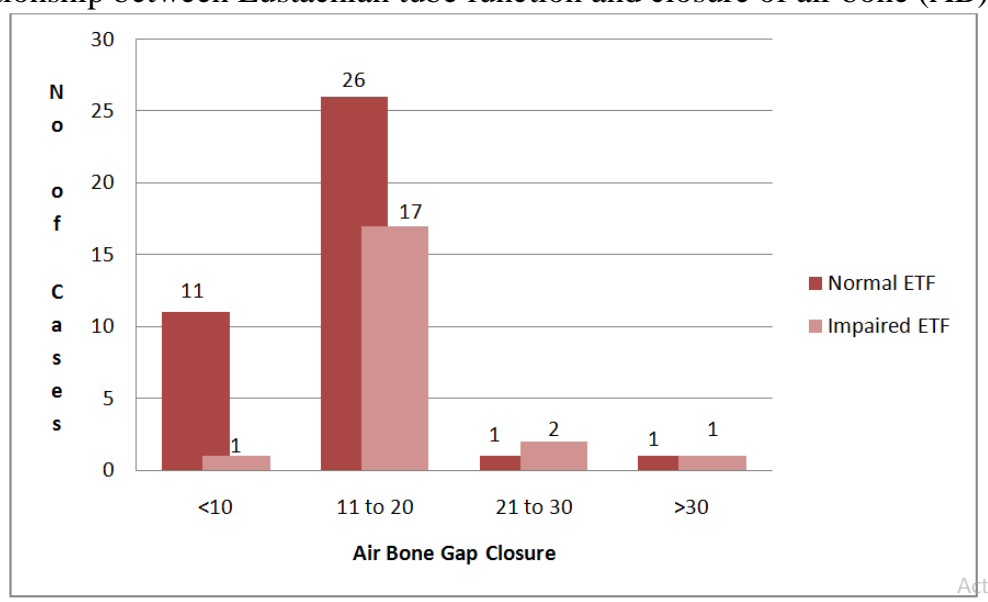

